\title{
See one, do one, teach one?
}

\author{
Michael J. Reardon, MD
}

From the Department of Cardiovascular Surgery, Houston Methodist Hospital, Houston, Tex. Disclosures: Author has nothing to disclose with regard to commercial support.

Received for publication Aug 5, 2018; accepted for publication Aug 10, 2018; available ahead of print Sept 25, 2018.

Address for reprints: Michael J. Reardon, MD, Department of Cardiovascular Surgery, Houston Methodist Hospital, 6550 Fannin, Suite 1401, Houston, TX 77030 (E-mail: mreardon@ houstonmethodist.org). J Thorac Cardiovasc Surg 2019;157:e45-6 0022-5223/ $\$ 36.00$

Copyright (C) 2018 by The American Association for Thoracic Surgery https://doi.org/10.1016/j.jtcvs.2018.08.022

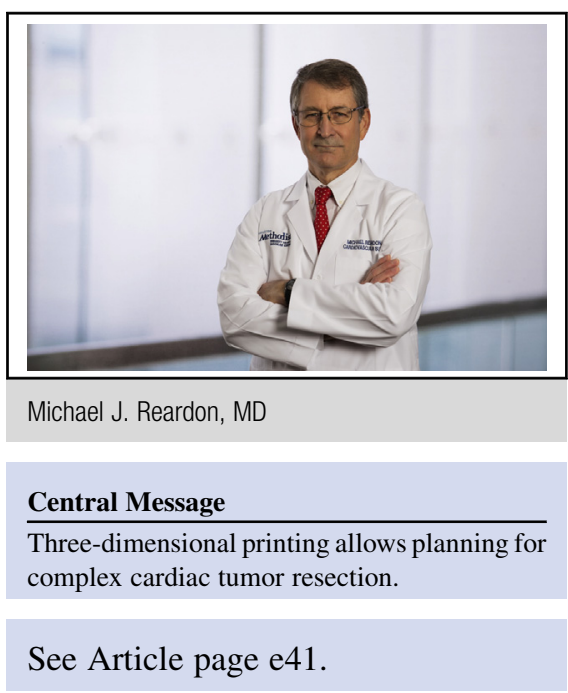

Cardiac surgeons often face challenges in the treatment of complex cardiac diseases. Excellence is honed by hours in the operating room gaining experience. As a surgery trainee and young surgeon, I was fortunate to watch master surgeons and then emulate them performing cases multiple times to improve my skills. But what should surgeons do for problems so uncommon that prior experience in limited or nonexistent? When faced with a unique surgical problem for the first time, see one, do one, teach one seems even more flippant? How can the surgeon make his or her first case as safe and successful as possible without prior experience?

Menegazzo and colleagues ${ }^{1}$ present an interesting and rare case of primary cardiac sarcoma involving the left atrium. Primary cardiac sarcoma is an uncommon and lethal disease with complete surgical resection representing the best opportunity for survival. ${ }^{2}$ Complete resection with pathologically negative margins has been shown to improve survival but can present significant challenges because not all cardiac structures can be safely resected or reconstructed. ${ }^{3}$ Left-sided sarcomas can present additional problems with exposure because of the posterior location of the left atrium and surrounding vital structures. Early in our experience with primary cardiac sarcoma, we noticed that the surgical literature contained a number of reports of left atrial sarcomas requiring multiple resections because of local recurrence. We hypothesized that this occurred because surgeons could not obtain adequate exposure to allow complete resection and safe reconstruction. We first used cardiac autotransplantation to address these issues in 1998. ${ }^{4}$ Our subsequent experience has shown that this approach indeed helped largely eliminate local recurrence and increase survival. ${ }^{5}$ Our interest in this disease has allowed our team to currently have operated on 119 primary cardiac sarcomas and continue to add novel approaches to our surgical techniques. ${ }^{6}$ Unfortunately, few surgeons or surgical teams have the opportunity for this experience before being faced with their first challenging cases. How best to prepare for a case you have never done before when making the wrong choice can mean disability or death for your patient? Ask your kids or grandkids.

When I watch my grandchildren play a new video game, they will run through the game until they fail. They reboot the game and try again using new strategies until they are finally successful. Hours of practice make them master of these games. This of course also happens in the adult world. The pilot of your last plane flight did not wait until they lost an engine to find out what this was like and how best to handle the situation. Professional pilots test emergency and difficult situations in flight simulators where if they crash they can reboot and try again until they master the problem. In surgery we do not have this luxury, because there is no reboot with human life. However, Menegazzo and colleagues ${ }^{1}$ have moved us a step closer by 3 -dimensional (3D) printing the heart with the tumor. We have previously used $3 \mathrm{D}$ printing of complex cardiac tumors to aid in planning surgical treatment and found this very helpful. ${ }^{7}$ Before surgery, the surgeon can examine in 3 dimensions the tumor and its relationship with other cardiac structure. Surgeons routinely take 3D imaging such as computed tomography or magnetic resonance scans and mentally build a model, but printing lets us physically build a model similar to the physical heart we will work on. The next step will be to take the 3D data set from the tumor imaging and build a 3D computer model that can be manipulated by the surgeon. When that can be done, the surgeon can practice an operation and, if unsuccessful, reboot and try again. Simulated surgery, like simulated plane flight, when adequately developed will likely become a 
major component of both training and surgical practice. I thank Dr Menegazzo and colleagues ${ }^{1}$ for moving us one step further along this important path. With this progress, we will then finally catch up to our grandkids, and see one, do one, teach one can happen electronically on the same data set without harming a patient.

\section{References}

1. Menegazzo WR, Alvarez J, Cusimano RJ, Geib G, Torres FS, Clausell N, et al. Modified autotransplant with three-dimensional printing for treatment of primary cardiac sarcoma. J Thorac Cardiovasc Surg. 2019;157:e41-3.
2. Ramlawi B, Leja MJ, Abu Saleh WK, Al Jabbari O, Benjamin R, Ravi V, et al. Surgical treatment of primary cardiac sarcomas: review of a single-institution experience. Ann Thorac Surg. 2016;101:698-702.

3. Abu Saleh WK, Ramlawi B, Shapira OM, Al Jabbari O, Ravi V, Benjamin R, et al. Improved outcomes with the evolution of a neoadjuvant chemotherapy approach to right heart sarcoma. Ann Thorac Surg. 2017;104:90-6.

4. Reardon MJ, DeFelice CA, Sheinbaum R, Baldwin JC. Cardiac autotransplant for surgical treatment of a malignant neoplasm. Ann Thorac Surg. 1999;67:1793-5.

5. Ramlawi B, Al-Jabbari O, Blau LN, Davies MG, Bruckner BA, Blackmon SH, et al. Autotransplantation for the resection of complex left heart tumors. Ann Thorac Surg. 2014;98:863-8.

6. Chan EY, Reul RM, Kim MP, Reardon MJ. The "Texas Two-Step" procedure. J Thorac Cardiovasc Surg. 2018;155:285-7.

7. Al Jabbari O, Abu Saleh WK, Patel AP, Igo SR, Reardon MJ. Use of threedimensional models to assist in the resection of malignant cardiac tumors. $J$ Card Surg. 2016;31:581-3. 